\title{
Predictive and prognostic value of 256-slice computed tomography angiography in patients with suspected coronary artery diseases
}

\author{
Rami M. Abazid, Ahmad Almeman ${ }^{1}$, Akram F Eldesoky, Habiba S. Alenzi ${ }^{2}$, Nora A. Altorbak ${ }^{2}$, Sarah A. Altorbak², \\ Bashayer Almotyri², Osama A. Smettei \\ Department of Cardiology, Prince Sultan Cardiac Center Qassim, King Fahad Specialist Hospital, Buraydah, Al-Qassim Province, \\ Saudi Arabia, 'Department of Pharmacology, College of Medicine, Qassim University, Qassim, Saudi Arabia, ${ }^{2}$ College of Medicine, \\ Qassim University, Buraydah, Saudi Arabia
}

\begin{tabular}{|c|}
\hline Access this article online \\
\hline Website: www.avicennajmed.com \\
\hline DOI: 10.4103/ajm.AJM_94_18 \\
\hline Quick Response Code: \\
\hline
\end{tabular}

\begin{abstract}
Background: Coronary computed tomography angiography (CCTA) is commonly used to diagnose coronary artery diseases (CADs). We aimed to determine the utility of CCTA among patients suspected with CAD at the Prince Sultan Cardiac Center Qassim. Materials and Methods: CCTA results of 425 cardiac patients, complaining of chest pain with suspected CAD, were used to classify coronary artery stenosis into two types: obstructive if the luminal stenosis was $\geq 50 \%$ or nonobstructive if it was $<50 \%$. Follow-ups were conducted through clinic or phone-based interviews to document any of the following endpoints: nonfatal myocardial infarctions (Mls) or cardiac deaths (CDs), representing the major cardiac events. All other cardiac cases, including hospitalization with unstable angina, and/or late coronary revascularization, were documented. Results: Patients with a normal coronary artery were $278(65.5 \%)$. The number of patients with nonobstructive and obstructive diseases was $85(20 \%)$ and $62(14.5 \%)$, respectively. After $19.6 \pm 7$ months of follow-up, 21 cardiac events occurred in twenty patients: five major adverse events (two CDs and three nonfatal MIs), ten hospitalizations due to unstable angina, and six late coronary revascularizations. Furthermore, the cumulative all-cardiac-event rates in patients with normal coronary arteries, nonobstructive $C A D$, and obstructive CAD were $3(1 \%), 7(8.2 \%)$, and $11(17.7 \%)$, respectively. However, patients with normal CCTA had no major cardiac events during the follow-up. Conclusion: CCTA can provide valuable prognostic information on patients with suspected CAD. Patients are likely to have excellent intermediate outcomes if the coronary arteries are confirmed to be normal by CCTA.
\end{abstract}

Key words: Angiography, coronary artery, prognosis

\section{INTRODUCTION}

Cardiovascular diseases are the leading causes of deaths worldwide, and coronary artery diseases (CADs) are the most common among them. Although the currently available management of CAD is effective in reducing cardiac deaths (CDs) ${ }^{[1]}$ early disease detection and identification of patients at risk, with subsequent application of proper preventive measures, is considered a more efficient method for reducing cardiovascular events. ${ }^{[2,3]}$ Coronary computed

Address for correspondence: Dr. Rami M. Abazid, Department of Cardiology, Cardiac Imaging, Prince Sultan Cardiac Center, Buraydah, Qassim, Saudi Arabia.

E-mail: ramiabazid@yahoo.com tomography angiography (CCTA), a noninvasive tool for ruling out $\mathrm{CAD}$, enables a comprehensive assessment of the coronary tree ${ }^{[4]}$ including lesion severity, extent, and atherosclerotic plaque components. ${ }^{[5]}$ CCTA can be used

This is an open access journal, and articles are distributed under the terms of the Creative Commons Attribution-NonCommercial-ShareAlike 4.0 License, which allows others to remix, tweak, and build upon the work non-commercially, as long as appropriate credit is given and the new creations are licensed under the identical terms.

For reprints contact: reprints@medknow.com

Cite this article as: Abazid RM, Almeman A, Eldesoky AF, Alenzi HS, Altorbak NA, Altorbak SA, et al. Predictive and prognostic value of 256-slice computed tomography angiography in patients with suspected coronary artery diseases. Avicenna J Med 2019;9:23-27. 
for stratification of individuals with suspected ischemic heart diseases. ${ }^{[5-8]}$ Multiple studies discuss the value of prognostication using CCTA, especially in patients with CAD. However, no similar studies have been conducted in Saudi Arabia. Therefore, we sought to investigate the prognosis of CAD using CCTA in patients with chest pain.

\section{MATERIALS AND METHODS}

\section{Patient selection}

The study recruited 425 consecutive patients with chief complaints of chest pain, who were suspected to have CAD. Between December 2012 and April 2016, all patients were referred for CCTA either from the outpatient clinic or enrolled during hospital admission. For this study, basic demographic variables, clinical data, family history of cardiovascular diseases, indications for CCTA, and follow-ups were obtained by a trained researcher blinded to the CCTA data, either using medical records or telephone interviews.

A total of 80 patients, 59 patients who were lost during the follow-up after CCTA, 12 patients who had only non-enhanced computed tomography (CT) done for calcium score, and 9 patients who had noninterpretable CCTA results due to the presence of artifacts, were excluded from the study. We obtained institutional ethical approval for the study before the conduction. The study was conducted in accordance with the Declaration of Helsinki.

\section{Coronary computed tomography angiography acquisition}

All CCTA was performed using 256-slice CCTA (Siemens Definition Flash ${ }^{\oplus}$, Siemens Healthcare, Forchheim, Germany). CCTA data were acquired while the patients held their breath during deep inspiration. We used beta-blockers before the scan to keep heart rate $<65$ beats $/ \mathrm{min}$. A test bolus technique, using $15 \mathrm{ml}$ of contrast agent, was flushed with a $30 \mathrm{ml}$ saline, at a flow rate of $5 \mathrm{ml} / \mathrm{s}$. Next, an injection of $80 \mathrm{ml}$ contrast agent, followed by a $50 \mathrm{ml}$ saline flush, at a flow rate of $5 \mathrm{ml} / \mathrm{s}$, was administered for CCTA.

\section{Coronary computed tomography angiography data analysis}

The Agatston method was used to assess the coronary calcium score. Then, the CCTA scans were reviewed by experienced cardiologists using commercially available software (Syngo, Multimodality Workplace, Siemens AG, Forchheim, Germany). The coronary arteries were divided into 16 segments as follows: 1 - left main coronary artery; 2 - proximal; 3 - mid; 4 - distal left anterior descending artery; 5 - proximal; 6 - mid; 7 - distal diagonal branch; 8 - proximal; 9 - mid; 10 - distal left circumflex coronary artery; 11 - proximal; 12 - mid; 13 - distal obtuse marginal branch; 14 - proximal; 15 - mid; and 16 - distal segments of the right coronary artery. ${ }^{[9]}$

Visual estimation was used to quantify the coronary lesions. Each segment was assessed by the maximum stenosis severity and graded based on the recommendation of the Society of Cardiovascular Computed Tomography as follows: minimal, mild, moderate, and severe, with luminal stenosis of $1 \%-24 \%, 25 \%-49 \%, 50 \%-69 \%$, and $\geq 70 \%$, respectively. ${ }^{[10]}$ In our study, any stenosis of more than $50 \%$ was considered obstructive CAD.

\section{Clinical follow-up}

The incidence of hard cardiac events was followed up in all patients, including CDs and/or nonfatal myocardial infarctions (MI). In addition, all cardiac events were recorded, including hard cardiac events, late coronary revascularization, and/or hospitalization for unstable angina. All documented deaths were considered cardiac in origin unless noncardiac causes were established. Late revascularization was defined as any coronary revascularization procedure carried out more than 90 days after CCTA. Nonfatal MI was defined as the existence of ischemic-like chest pain, typical electrocardiogram changes, and elevated cardiac enzymes.

\section{Statistic al analysis}

The mean \pm standard deviation was used to describe the quantitative data, whereas the categorical data were described as percentages. We used the two-sample Student's $t$-test to analyze the normally distributed data, whereas the Chi-square test was used for association when required. We assessed the cumulative event-free survival rates over the follow-up period using the Kaplan-Meier method. Patients were categorized based on the vessel involvement as follows: single-vessel disease (1-VD), 2-VD, and 3-VD. Consequently, the survival curves of all cardiac events were compared using the log-rank test. $P<0.05$ was considered statistically significant and our level of significance was set at 0.90. All the data were analyzed by SPSS version 19.0 (SPSS Inc., Chicago, Illinois, USA).

\section{RESULTS}

\section{Baseline characteristics}

A total of 425 patients completed the study in a median of 20 months (13.5-26.6 months). Among them, 262 (61.5\%) were male with a mean age of $49 \pm 12$ years. The indications for CCTA were chest pain in $365(86 \%)$ patients, shortness of breath in $51(12 \%)$ patients, and abnormal stress test in $9(2 \%)$ patients. The baseline characteristics are shown in Table 1. 


\section{Cardiac computed tomography angiography}

We found through CCTA that normal coronary arteries existed in $278(65.5 \%)$ patients, whereas 85 (20\%) patients had nonobstructive CAD with $<50 \%$ stenosis, and 62 (14.5\%) patients had obstructive CAD with $\geq 50 \%$ luminal stenosis. Other CCTA findings are shown in Table 1.

\section{Survival analysis}

During the follow-up period, 21 cardiac events occurred in twenty patients: two CDs, three nonfatal MIs, ten cases of hospitalization due to unstable angina, and six cases of late coronary revascularizations. The cumulative number of cardiac events was as follows: $3(1 \%)$ in patients with normal CCTA, $7(8.2 \%)$ in patients with nonobstructive CAD, and $11(17.7 \%)$ in patients with obstructive CAD.

Furthermore, we found that patients with cardiac events were significantly older ( $51 \pm 14$ vs. $49 \pm 12$ years, $P=0.047$ ) and mostly men (19 (90)\% vs. $244(60 \%), P=0.028)$. These patients tended to have significantly higher calcium

\begin{tabular}{|c|c|}
\hline \multicolumn{2}{|l|}{ Table I: Baseline characteristics } \\
\hline Age (years), mean $\pm S D$ & $49 \pm 12$ \\
\hline Male sex, $n(\%)$ & $262(6 \mid .5)$ \\
\hline Body mass index $\left(\mathrm{kg} / \mathrm{m}^{2}\right)$, mean $\pm \mathrm{SD}$ & $30.6 \pm 5.4$ \\
\hline Diabetes mellitus, $\mathrm{n}(\%)$ & $|2|(28.5)$ \\
\hline Hypertension, $n(\%)$ & I8I (42.6) \\
\hline Dyslipidemia, $n(\%)$ & $37(8.7)$ \\
\hline Family history of CAD, $n(\%)$ & $8(2)$ \\
\hline Current smoking, $n(\%)$ & $44(10.4)$ \\
\hline Cholesterol $(\mathrm{mmol} / \mathrm{l})$, mean $\pm \mathrm{SD}$ & $4.1 \pm 1.5$ \\
\hline $\mathrm{LDL}(\mathrm{mmol} / \mathrm{l})$, mean $\pm \mathrm{SD}$ & $2.7 \pm 1.2$ \\
\hline $\mathrm{HDL}(\mathrm{mmol} / \mathrm{l})$, mean $\pm \mathrm{SD}$ & $|.2 \pm 0.3|$ \\
\hline \multicolumn{2}{|l|}{ CT data } \\
\hline Calcium score mean (minimum-maximum) & $22(0-1537)$ \\
\hline Normal coronary arteries, $n(\%)$ & $278(65.5)$ \\
\hline Nonobstructive CAD, $n(\%)$ & $85(20)$ \\
\hline Obstructive CAD, $n(\%)$ & $62(14.5)$ \\
\hline $\mathrm{I}-\mathrm{VD}, n(\%)$ & $34(8.0)$ \\
\hline $2-V D, n(\%)$ & $12(2.8)$ \\
\hline 3-VD or significant left mean disease & $16(3.7)$ \\
\hline CAD stenosis $\geq 70 \%$ & $36(8.5)$ \\
\hline
\end{tabular}

scores when compared to patients with no documented cardiac events (115 \pm 170 vs. $18 \pm 69 \mathrm{HU}, P \leq 0.0001)$, respectively [Table 2 ].

In Kaplan-Meier curves, and during the median 20-month follow-up, the cumulative all event-free survival rates were $98.9 \%$ in patients with normal CCTA versus $88.4 \%$ in patients with a coronary stenosis of any severity [Figure 1]. In addition, we found that patients with nonobstructive CAD have a significantly higher rate of all event-free survival when compared to obstructive CAD (96.5\% vs. $77.4 \%, P<0.0001$ ) [Figure 1]. Furthermore, the cumulative free-survival rates were significantly higher with an increased number of affected coronary arteries $(82.4 \%$ with $1-\mathrm{VD}, 83.3 \%$ with 2 -VD, and $62.5 \%$ with 3-VD $[P<0.0001])$.

More importantly, major cardiac events were not reported when coronary arteries were normal. Univariate logistic regression showed that age, male sex, a coronary calcium score $>0$, and the existence of luminal coronary stenosis were independent predictors of cardiac events. Moreover, multivariate regression, adjusted to age and gender, showed that 3-VD and obstructive CAD were also independent predictors of cardiac events [Table 3].

\section{DISCUSSION}

In this study, we found that noninvasive coronary imaging using CCTA can provide valuable prognostic information on symptomatic patients, with suspected CAD. Importantly, patients with normal CCTA had an excellent prognosis without any major cardiac events at the 20-month follow-up. Conversely, the majority of documented cardiac events occurred in patients with coronary stenosis of $50 \%$ or more, particularly in those with 3-VD.

CCTA in coronary stenosis is a reliable tool with an excellent negative predictive value. In addition, it can

\begin{tabular}{|c|c|c|c|}
\hline Variables & Patients without events & Patients with events & $\boldsymbol{P}$ \\
\hline Number of patients (\%) & $405(95.3)$ & $20(4.7)$ & \\
\hline Sex men $(\%)$ & $244(60)$ & $18(90)$ & 0.028 \\
\hline Age (years), mean $\pm S D$ & $49 \pm 12$ & $51 \pm 14$ & 0.047 \\
\hline Diabetes mellitus, $n(\%)$ & $112(28)$ & $9(45)$ & 0.093 \\
\hline Hypertension, $n(\%)$ & $170(42)$ & $11(55)$ & 0.25 \\
\hline Dyslipidemia, $n$ (\%) & $35(8.6)$ & $2(10)$ & 0.66 \\
\hline Family history of coronary artery disease, $n(\%)$ & $7(2)$ & I (5) & 0.54 \\
\hline Current smoking, $n(\%)$ & $40(10)$ & $4(20)$ & 0.15 \\
\hline Calcium score, mean $\pm S D$ & $18 \pm 69$ & $115 \pm 170$ & $<0.000$ । \\
\hline Any coronary stenosis & $130(32)$ & $17(85)$ & $<0.0001$ \\
\hline Coronary stenosis $\geq 50 \%, n(\%)$ & $48(12)$ & $14(70)$ & $<0.0001$ \\
\hline
\end{tabular}




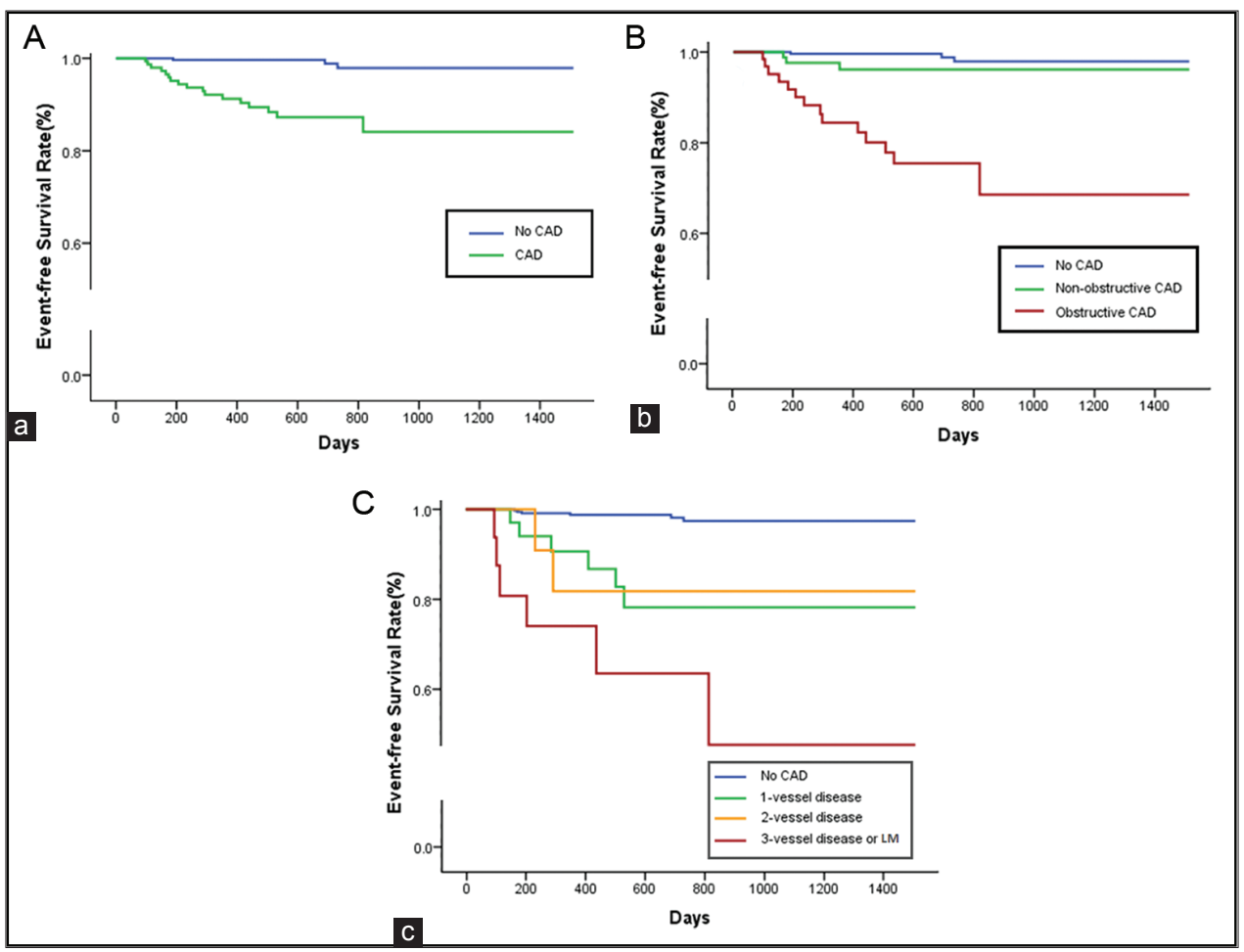

Figure 1: Survival curves for (a) normal coronary arteries and coronary artery disease. (b) Nonobstructive coronary artery disease and obstructive coronary artery disease. (c) Numbers of vessels with obstructive coronary artery disease. The numbers in each figure represent the 22-month event-free survival rates

\begin{tabular}{|c|c|c|c|c|}
\hline Variable & Unadjusted HR (95\% CI) & $\boldsymbol{P}$ & Adjusted $^{\mathrm{a}} \mathrm{HR}(95 \% \mathrm{Cl})$ & $\mathbf{P}$ \\
\hline Any coronary stenosis & $\mid 2.048(3.448-4 \mid .666)$ & $<0.0001$ & $2.501(0.473-13.157)$ & 0.28 \\
\hline Any obstructive coronary $\geq 50 \%$ stenosis & I7.354 (6.367-47.30I) & $<0.0001$ & $5.847(1.443-23.809)$ & 0.013 \\
\hline Three-vessel obstructive CAD & $16.949(5.405-52.63 \mid)$ & $<0.0001$ & $2.673(1.587-7.397)$ & 0.018 \\
\hline Calcium score $>0$ & $1.003(1.000-1.006)$ & 0.025 & & \\
\hline Age (years) & $1.045(1.005-1.087)$ & 0.029 & $1.027(0.982-1.074)$ & 0.24 \\
\hline Male & $5.939(1.395-25.94 I)$ & 0.018 & $6.225(1.289-30.062)$ & 0.023 \\
\hline Diabetes & $0.467(0.189-1.158)$ & 0.1 & & \\
\hline Hypertension & $0.592(0.240-1.460)$ & 0.25 & & \\
\hline Family history & $7.053(0.700-71.014)$ & 0.29 & & \\
\hline Smoking & $0.438(0.140-1.375)$ & 0.15 & & \\
\hline Dyslipidemia & $0.346(0.074-1.630)$ & 0.18 & & \\
\hline
\end{tabular}

${ }^{2}$ Analysis adjusted for age and sex. SD: Standard deviation, CAD: Coronary artery disease, HR: Hazard ratio, Cl: Confidence interval

provide a comprehensive evaluation of the extent and types of atherosclerotic plaque ${ }^{[4]}$ and can help in planning the revascularization procedure. ${ }^{[1,12]}$ Multiple studies showed that CCTA could precisely predict adverse cardiovascular outcomes and the combined endpoint, including all-cause mortality. Of particular interest, the study by Andreini et al. ${ }^{[13]}$ demonstrated that normal CCTA has an excellent prognostic value with very low annual event rate at 52-month follow-up. Furthermore, CONFIRM (COronary CT Angiography EvaluatioN For Clinical Outcomes: An InteRnational Multicenter) registry, showed that both plaque burden and a stenosis of more than 50\%, particularly in any proximal segment, carry an incremental prognostic value for CCTA in predicting the cardiac events. ${ }^{[14]}$ Moreover, Hou et al. ${ }^{[15]}$ found that the 3-year cumulative cardiovascular events increase with an increasing number of stenosed vessels.

Our findings support the result of the previous reports, which showed that obstructive CAD is well associated with increased cardiovascular events at the 20-month follow-up, and in contrast to previous reports, only a 256-slice machine was used to perform CCTAs in our analysis.

Our study has several limitations. First, the number of cardiac events was small. Second, the median follow-up was 20 months; hence, long-term follow-up is required in the future. Third, our study utilized a single center for 
analysis; therefore, multicenter studies with larger numbers of patients should be conducted.

\section{CONCLUSION}

CCTA provided incremental prognostic information on individuals with suspected CAD. Adverse cardiovascular events are extremely low with normal CCTA at the 20-month follow-up.

\section{Financial support and sponsorship}

Nil.

\section{Conflicts of interest}

There are no conflicts of interest.

\section{REFERENCES}

1. World Health Organization, The World Health Report 2002: Reducing Risks, Promoting Healthy Life. Geneva: World Health Organization; 2002.

2. Ho WK, Hankey GJ, Eikelboom JW. Prevention of coronary heart disease with aspirin and clopidogrel: Efficacy, safety, costs and cost-effectiveness. Expert Opin Pharmacother 2004;5:493-503.

3. Collins R, Armitage J, Parish S, Sleigh P, Peto R, Heart Protection Study Collaborative Group. et al. MRC/BHF heart protection study of cholesterol-lowering with simvastatin in 5963 people with diabetes: A randomised placebo-controlled trial. Lancet 2003;361:2005-16.

4. Budoff MJ, Dowe D, Jollis JG, Gitter M, Sutherland J, Halamert E, et al. Diagnostic performance of 64-multidetector row coronary computed tomographic angiography for evaluation of coronary artery stenosis in individuals without known coronary artery disease: Results from the prospective multicenter ACCURACY (Assessment by coronary computed tomographic angiography of individuals undergoing invasive coronary angiography) trial. J Am Coll Cardiol 2008;52:1724-32.

5. Al-Mallah MH, Aljizeeri A, Villines TC, Srichai MB, Alsaileek A. Cardiac computed tomography in current cardiology guidelines. J Cardiovasc
Comput Tomogr 2015;9:514-23.

6. Al-Mallah MH, Qureshi W, Pantelic M, Nour K. Long term prognostic value of Coronary Computed Tomography Angiography in suspected coronary artery disease: a 62 month median follow-up study. International journal of cardiology 2014;176:1244-6. Doi: 10.1016/j. ijcard.2014.07.203.

7. van Werkhoven JM, Schuijf JD, Gaemperli O, Jukema JW, Boersma E, Wijns W, et al. Prognostic value of multislice computed tomography and gated single-photon emission computed tomography in patients with suspected coronary artery disease. J Am Coll Cardiol 2009;53:623-32.

8. Shaw LJ, Berman DS, Hendel RC, Borges Neto S, Min JK, Callister TQ, et al. Prognosis by coronary computed tomographic angiography: Matched comparison with myocardial perfusion single-photon emission computed tomography. J Cardiovasc Comput Tomogr 2008;2:93-101.

9. Austen WG, Edwards JE, Frye RL, Gensini GG, Gott VL, Griffith LS, et al. A reporting system on patients evaluated for coronary artery disease. Report of the Ad Hoc Committee for Grading of Coronary Artery Disease, Council on Cardiovascular Surgery, American Heart Association. Circulation 1975;51:5-40.

10. Raff GL, Abidov A, Achenbach S, Berman DS, Boxt LM, Budoff MJ, et al. SCCT guidelines for the interpretation and reporting of coronary computed tomographic angiography. J Cardiovasc Comput Tomogr 2009;3:122-36.

11. Abazid RM, Smettei OA, Khalaf HH, Soomro T, Ali Dar M, Tamim M, et al. The role of computed tomographic angiography in predicting left anterior descending artery graftability when catheter angiography is inconclusive. J Thorac Imaging 2018;33:55-9.

12. Opolski MP. Cardiac computed tomography for planning revascularization procedures. J Thorac Imaging 2018;33:35-54.

13. Andreini D, Pontone G, Mushtaq S, Bartorelli AL, Bertella E, Antonioli L, et al. A long-term prognostic value of coronary CT angiography in suspected coronary artery disease. JACC Cardiovasc Imaging 2012;5:690-701.

14. Hadamitzky M, Achenbach S, Al-Mallah M, Berman D, Budoff M, Cademartiri F, et al. Optimized prognostic score for coronary computed tomographic angiography: Results from the CONFIRM registry (COronary CT angiography evaluation for clinical outcomes: An inteRnational multicenter registry). J Am Coll Cardiol 2013;62:468-76.

15. Hou ZH, Lu B, Gao Y, Jiang SL, Wang Y, Li W, et al. Prognostic value of coronary $\mathrm{CT}$ angiography and calcium score for major adverse cardiac events in outpatients. JACC Cardiovasc Imaging 2012;5:990-9. 